the small of the back, as the father put it, constipation, frequent and painful micturition. The temperature was less than $100 \mathrm{~F}$., pulse was somewhat accelerated. The general appearance was that of one who had suffered long and patiently.

Examination.--I suggested to the mother that a more thorough examination of the child be made, to which she readily consented. In the outward appearance of the vulva there was nothing to attract special attention, except that the tissues were slightly inflamed; on pressure some tenderness was found to exist. On separating the labia a mucopurulent discharge was detected. Here the mother admitted that the child had suffered from leucorrhea for a month or more. With a small eyelet probe I managed to secure a sample of the discharge for examination. A microscopic examination of the discharge (Gram's method) was made and gonococei were found.

Treatment.-I put the child on a milk and other liquid diet, and prescribed a tonic treatment, an alkaline preparation for neutralizing the urine, and absolute rest in bed. Locally $r$ prescribed a wash of permanganate of potash, 1 to 10,000 , given by means of a small rubber syringe, three or four times daily; after each washing a small pledget of absorbent cotton, dusted with boracic acid, was placed in the vagina in such a way as to separate the labia. The child made a rapid recovery.

CASE 2.-This case is a little more interesting inasmuch as it occurred in a child of less than 4 years of age.

Patient.-Child, white, aged 31/2. Previous history unimportant. This child had been under the care of a physician for over two weeks and had been treated for worms, general debility and cystitis, but without results.

History.-This was similar to that in the former case. I proposed a thorough examination of the child, but the parents objecting, I refused to be further consulted until I was allowed to make such examinations as I saw fit and the parents de: parted. The following morning I was called to their home to make such examinations as $I$ saw fit.

Examination.-The entire vulva was highly inflamed and tender to pressure; the inner portions of the thighs were likewise red and somewhat tender. On separating the labia a creamy discharge oozed freely from the vagina. A small pledget of cotton was passed into the vagina and withdrawn saturated with the discharge. Microscopic examination (Gram's method) revealed gonococci.

Treatment.-The child was put on a milk diet, plenty of pure, fresh air, tonics, bowels opened freely, and absolute rest required. A neutralizing nreparation was given to render the urine bland. Locally I preseribed a wash three or four times daily, of protargol 1 per cent., given by means of a small rubber syringe. After each washing a small pledget of absorbent cotton, dusted with boracic acid, was placed in the vagina in such a way as thoroughly to separate the labia. So far, this child seems to have recovered.

\section{HYSTERIA OR MALINGERING IN A GIRL OF TEN YEARS.}

FLAVEL 13. TIFFANY, A.M., M.D

Professor of Ophthalmology, University Medical College. KANSAS CITY, MO.

In the light of my experience of more than a quartes of a century in the practice of ophthalmolngy this seems to me a unique case of unusual interest. The question is: Is it likely that this is a case of hysteria in a child of 10 years, with no manifestation or evidence of any immediate approach of the catamenia?

Paticnt.-.Miriam G., aged 10, of light complexion, blue eyes, from Kansas, was brought by her father to consult me Jan. 8, 1907.

History. - The father stated that up to the week previous the child had seemingly good eyes with good vision, but last Friday, January 4, she came from school and said that during the afternoon, while studying, the page suddenly became red. Thereafter she complained of all colors appearing red, with the exception of objects of red color, which looked white. She spoke of the red brick sidewalk looking white, whereas the light gray pavement was red. While in my office the father designated several articles of red color and she would in. stantly call them white, or he would point to some white object and she would say it was red.

Tests.-I suspected malingcring at once and placed the patient twenty feet from a white light and asked her the color of the lamp; she instantly called it red. I then put on a trial frame and inserted a green lens, but she said the light still looked red. I then inserted a red lens; at first she said the light looked white, but finally said, when $I$ put in another lens of the same shade, that one was a light red and one a dark red. I then suggested to her that I should place a lens in the trial frame which would correct the color blindness. With a plano before her eye she would name all colors correctly. I then tested her with the different colored yarns. She at first called all of them red, excepting the red skein, which she called white. I again suggested to her that I could correct the defect by glasses and once more placed the plano glasses before her eyes; then she named, as I pointed to them, the colors correctly. The child had a slight convergent strabismus with hypermetropia, and I suggested to the father that an operation to straighten the eyes would also effect a cure of the color blindness. Whether the fear of an operation influenced the child $I$ do not know, but on January 9, at 5 o'clock, the color blindness, the father said, disappeared as suddenly as it came. This the child also related to me when she called at my office, January 10 .

If this phenomenon had occurred in a willful, intractable, disobedient child, one would not have been so baffled for a cause of the malingering, but $M$. is a modest, obedient, rather retiring little girl of an excellent family.

I prescribed glasses for the existing hypermetropia and allowed the child to go home, advising them, however, to return in six weeks that I might keep the case under surveillance.

80j M.cGee Street.

\section{THE PASSAGE OF METHYLENE BLUE FROM THE MATERNAL TO THE FETAL CIRCULATION.}

\section{S. H. CORRIGAN, M.D.}

SIOUX FALLS, S. D.

Failure to find record of any similar observation in the study of placento-maternal circulation would seem sufficient reason for submitting the following:

A woman, three months pregnant, suffering much from a chronic cystitis, was given a capsule of methylene blue compound. As the medicine produced almost complete relief of symptoms, the patient continued taking it up to the time of her delivery, at full term. The average dosage given her was three grains of the methylene blue daily. At delivery the baby, an unusually vigorous child, attracted no special attention, but when the nurse was removing the first diaper she noticed a blue stain on the cotton; each subsequent change of diaper during the first eighty hours after birth gave evidence of methylene blue in the infant's urine, the color gradually disappearing. Nothing else unusual was found in the baby's condition. It was noticed that the liquor amnii showed no unusual color; careful inspection of the sheets and pads used during labor failed to show any trace of color from methylene blue.

From these observations I may perhaps venture to assert:

1. Methylene blue passes from the circulation of the mother to that of the fetus.

2. Either the amount thus passing is an exceedingly small portion of the drug absorbed by the mother or the drug passes from mother to child and vice versa. 
During six months the mother received into her' stomach about nine drams of methylene blue, while an estimate based roughly on the amount of colored urine passed by the infant would place the quantity of the drug in the child's body at time of birth not above one grain.

3. There being no evidence of methylene blue in the liquor amnit, the fetus does not evacuate the bladder, and the liquor amnii accordingly is in no degree composed of fetal urine.

4. The kidneys of the child in utero do not secrete urine beyond that found in the bladder at the time of delivery, or. if they do secrete urine beyond this amount, they do not excrete methylene blue, which may be in the fetal circulation.

The first evacuation of the bladder in this case, occurring very shortly after birth, produced the characteristic stain. So it would seem that the kidneys not only secreted urine but also excreted methylene blue, while the child was still in utero, but not more than that contained in the bladder at the time of delivery.

\section{APHONIA OF UNKNOWN ORIGIN AND OF SIA MONTHS' DURATION IN A TWO AND ONE- HALF-YEAR-OLD CIIILD;}

\section{DISCOVERY OF AN OPEN SAFETY PIN IN THE LARYNX."}

JAMES T. CAMPBELL, M.N

Professor of Otology, Rhinology and Laryngology in the Post Graduate Medical School, Chicago.

$$
\text { CHICAGO. }
$$

Aphonia is most often due to an inflammation of the larynx when the swollen tissues interfere with free approximation of the vocal cords, to new growths, to a neurosis, or to a paralysis of the recurrent laryngeal nerve. A foreign body in the larynx causing aphonia is rare indeed; yet a complete collection of all the foreign bodies which, at one time or another, have found their way into the larynx would, probably, comprise specimens of every known substance.

\section{ETIOLOGY.}

Food products generally gain entrance during mastication while the person is laughing or talking. Metallic substances are occasionally impacted in the larynges of children while they are amusing themselves by putting coins, buttons, toys, etc., in their mouths. In rarer instances, teeth and tooth-plates become loosened during sleep and are drawn into the glottis.

Foreign bodies may also become fixed in the larynx, having previously passed upward through the trachea or esophagus. Edwards ${ }^{1}$ relates the curious case of a boy in whom a bronchial gland became detached, passed by an ulcerated opening into one of the bronchi, and was thence expelled up the trachea, and became impacted in the rima glottidis.

Some idea of the frequency with which foreign matters become fixed in the different parts of the air passages may be gathered from a report made by Bourdillat ${ }^{2}$ of 166 cases, in which analysis 80 cascs were of foreign bodies arrested in the trachea, 35 in the larynx, 26 in the right bronchus and 15 in the left bronchus.

* Read before the Chicago Laryngrological and Otological socisty, Dec. 11. 1906.

1. Med and Chir. Transactions, xxxyi.

2. IcKenzif : Diseases of the Pharynx, Larynx and Tractea

\section{SYMPTOMS}

The symptoms vary according to the size and shape of the foreign body. If fixed in the rima glottidis and large enough to fill the opening, death is almost instantaneous, unless the convulsive respiratory efforts of the patient succeed in dislodging it. On the other hand, small bodies such as fish bones, may remain in the larynx for an indefinite length of time without interrupting respiration and will merely give rise to coughing and a sensation of discomfort. Sharp and angular bodies cause very acute and continuous pain when they become so impacted as to press against the contiguous soft parts. Generally great anxiety and terror on the part of the patient accompany the entrance of any foreign body, howcver small, into the air passages and in many cases somewhat disguise the real importance of the accident.

\section{DIAGNOSIS.}

As a rule, the history of the case is clear and laryngoscopic examination verifies or disproves the statement made by the patient. In children and hysterical women a correct diagnosis can not always be made immediately and at such times a skiagraph should decide the case in question.

There is always great danger while the foreign body remains in the air passages or larynx. It may become dislodged and assuming an altered position close the glottis and suffocate the patient. There is danger also of inflammation and tumefaction of the soft parts of the larynx which may cause more gradually the same result. Even after the foreign body is removed one should give a guarded prognosis as long as there are symptoms of local inflammation.

History.-Ruth J., aged 2, in January, 1906, was given a dose of castor oil by her father, while her mother held her. Violent coughing immediately ensued and persistent aphonia resulted; it was thought by her parents and by the local phy. sicians that during the child's struggles the oil had been inspired into the larynx. They expected that with the advent of warm weather speech would return, but in this they were disappointed, and on Sept. 3, 1906, she was brought to me.

Examination.-On that day I was unable to make a laryngoscopic examination, but on the day following, at the PostGraduate Hospital, she was anesthetized and with the laryn. geal mirror I saw a metallic body lying on the upper surface of the right vocal cord.

Remoral and Recovery.-With the Schroetter tube forceps I grasped this body and withdrew an open safety-pin, which was $23 \mathrm{~mm}$. in length and $15 \mathrm{~mm}$. in extreme breadth. The pin point and the looped hinge were held fast in the respective ventricles of the larynx. The child was cared for at the hospital for thirty-six hours and was then allowed to go home, speaking as plainly as before the castor-oil episode. The mother had no knowledge of a safety-pin being about her own or the baby girl's clothing, but probably it was crowded into the child's mouth during her struggles to escape the castor oil, and then drawn into the larynx during a forcible inspiration.

\section{Washington Street.}

The Blood During Pregnancy After Splenectomy.-Cova reports in Ginecologia, iii, 716, 1906, the findings in regard to the blood in a woman who became pregnant about a year after removal of the spleen on account of malarial enlargement. She was in good health thereafter. The number of red corpuscles and the number of whites were approximately normal throughout the pregnancy, as also the percentage of hemoglobin, but the proportion between the white leucocytes differed somewhat from normal. Polynuclear forms were abnormally abundant, while lymphocytes were scanty. Eosinophile leucocytes also abounded and increased in numbers during the confinement, while the red corpuscles showed somewhat reduced resisting powers. 